\title{
Structural and optical characterization of Sm-doped ZnO nanoparticles
}

\author{
H E OKUR ${ }^{1, *}$, N BULUT ${ }^{2}$, T ATES ${ }^{2}$ and O KAYGILI ${ }^{2}$ \\ ${ }^{1}$ Department of Chemistry, Bursa Technical University, Bursa 16310, Turkey \\ ${ }^{2}$ Department of Physics, Faculty of Science, Firat University, Elazig 23119, Turkey \\ *Author for correspondence (esma.okur@btu.edu.tr)
}

MS received 30 November 2018; accepted 25 February 2019

\begin{abstract}
Micro-structural changes in zinc oxide $(\mathrm{ZnO})$ nanoparticles induced by the substitution of $\mathrm{Zn}^{2+}$ in $\mathrm{ZnO}$ by a rare earth (RE) metal ion, $\mathrm{Sm}^{3+}$, are investigated. Both pristine and $\mathrm{Sm}$-doped $\mathrm{ZnO}$ with a nominal doping concentration of 1,2 and $4 \%$ of Sm using a simple wet-chemical synthetic route followed by calcination at a high temperature of $900^{\circ} \mathrm{C}$, are synthesized. Structural investigations are primarily conducted using X-ray powder diffraction (XRPD) and scanning electron microscopy techniques. Evolution of structural parameters (unit cell parameters, average crystallite size, crystallinity percentage, lattice strain, stress, energy density and atomic packing factor) upon Sm doping is investigated together with Rietveld refinement and Le Bail analysis techniques. XRPD data confirmed that the synthesized nanostructures crystallize in a wurtzite hexagonal structure, the dopant $\mathrm{Sm}$ is incorporated into the Zn lattice and the annealing treatment plays a crucial role in determining the structural and optical properties of RE-metal-doped nanoparticles. Values of the optical band gap energy estimated from optical absorbance measurements reveal a widening of the band gap.
\end{abstract}

Keywords. X-ray powder diffraction; Rietveld analysis; Le Bail analysis; zinc oxide nanoparticles; doping effects.

\section{Introduction}

The correlation between the properties of solids and their size and shape on the atomic scale has been exploited for decades and it is well-established that nanostructured systems encompass a varied range of materials and/or devices that show various phenomena which are controlled by the manipulation of their microstructure on the atomic scale [1]. Zinc oxide, $\mathrm{ZnO}$ nanostructures are one of these materials exhibiting characteristic properties that allow a wide range of applications [2-5]. $\mathrm{ZnO}$ is a II-IV semi-conducting compound with a large band gap of $3.37 \mathrm{eV}$ at room temperature and a high exciton binding energy of $60 \mathrm{meV}$ [6-8]; therefore, it is popular for short wavelength applications in optoelectronics, such as light-emitting diodes [9], UV-laser diodes [10] and solar cells [11]. For semiconducting oxides, as a tuning parameter to control the energy gap, doping with metals has been a favoured method. Various transition metals (TMs), e.g., Fe [12], Co, Mn [13], Ni [14], Cu [15] and $\mathrm{Ag}$ [16], have been used as dopants to reduce the energy gap in stoichiometric $\mathrm{ZnO}$ and enhance the magnetic and performance properties. Indeed, room temperature ferromagnetism has been predicted in TM-doped $\mathrm{ZnO}$ compounds. Nevertheless, due to the conflicting reports on expected ferromagnetism and the low-Curie temperature [17,18], TM-doped $\mathrm{ZnO}$ compounds are not considered as suitable candidates for practical applications. Instead, rare earth (RE) metals are known to be better candidates as dopants due to their optical and high conductivity properties $[19,20]$ and the existence of partially filled f-orbitals which carry magnetic moments and can couple magnetically. Therefore, various synthetic efforts have been made for doping of RE metals (e.g., Er, Eu, Gd, $\mathrm{Nd}, \mathrm{Ce}, \mathrm{Dy}, \mathrm{Ho}, \mathrm{Pr}, \mathrm{Sm}, \mathrm{Yb}$ and $\mathrm{Tb}$ ) and different functional and magnetic properties have been reported depending on the nature of the dopant species and the way that the doping is carried out [21], i.e., low-temperature hydrothermal [22], chemical bath deposition [23], vapour phase transport [24], sol-gel [25] and wet-chemical methods [26].

In this study, the water-based wet-chemical synthetic technique was employed to prepare pristine and doped $\mathrm{ZnO}$ nanoparticles; Sm was used as a dopant with five electrons in $\mathrm{f}$ orbitals. A water-based wet-chemical synthetic route can offer some advantages over the low-temperature hydrothermal and wet chemical methods, e.g., environmentally favoured, lowcost and easy to handle starting reactants, simple reaction conditions and low-energy inputs. In this study, we experimentally investigated the influence of Sm concentration on the morphology, microstructure and optical band gap of $\mathrm{ZnO}$ nanoparticles.

\section{Experimental}

\subsection{Synthesis}

Zinc nitrate hexahydrate $\left(\mathrm{ZN}, \mathrm{Zn}\left(\mathrm{NO}_{3}\right)_{2} \cdot 6 \mathrm{H}_{2} \mathrm{O}\right)$, samarium(III) nitrate hexahydrate $\left(\mathrm{SN}, \mathrm{Sm}\left(\mathrm{NO}_{3}\right)_{3} \cdot 6 \mathrm{H}_{2} \mathrm{O}\right)$ and 
ammonia $\left(\mathrm{NH}_{3}\right)$ were purchased from Sigma-Aldrich and used as received without any further purification. $40-x \mathrm{mmol}$ $\mathrm{ZN}$ and $x \mathrm{mmol} \mathrm{SN}$ solution were dissolved in distilled water (total volume of the solution is $50 \mathrm{ml}$ ). The $\mathrm{pH}$ of the solution was adjusted to the value of 10.5 by adding ammonia. Then, this solution was stirred continuously in a magnetic stirrer without heating for $1.5 \mathrm{~h}$, placed into an oven at $120^{\circ} \mathrm{C}$ and annealed at this temperature for $25 \mathrm{~h}$ to completely remove the water in the samples. This was then followed by calcination of the dried powders in an electric furnace at $900^{\circ} \mathrm{C}$ for $2 \mathrm{~h}$. Four samples were prepared with $x=0,0.4,0.8$ and 1.6 $\mathrm{mmol}$ and were labelled as $\mathrm{ZnO}, 1 \mathrm{Sm}-\mathrm{ZnO}(1 \%), 2 \mathrm{Sm}-\mathrm{ZnO}$ $(2 \%)$ and $4 \mathrm{Sm}-\mathrm{ZnO}(4 \%)$, respectively.

\section{$2.2 X R P D$}

$\mathrm{X}$-ray powder diffraction (XRPD) data of pristine $\mathrm{ZnO}$ and $\mathrm{ZnO}: \mathrm{Sm}$ powders were collected at room temperature using a Rigaku RadB-DMAX II model diffractometer equipped with Bragg-Brentano geometry, over an angular range of $2 \theta=20-80^{\circ}$ with a step size of $0.02^{\circ}$ (CuK $\alpha$ radiation; $\lambda=1.54056 \AA$ ). The collected XRPD on pristine $\mathrm{ZnO}$ was analysed using the Rietveld refinement technique, which is termed as a whole powder pattern fitting method with the structure used to calculate peak intensities. An alternative approach to fit a model to powder diffraction data, where, in contrast, the structure is not used, but to employ a whole powder pattern decomposition method, such as Le Bail fitting. The Le Bail technique was employed for the analysis of the XRPD data collected on Sm-doped $\mathrm{ZnO}$ powders to extract reliable peak intensities. Both are least-squares algorithmbased techniques to optimize the fit between the observed data points and a calculated diffraction pattern by adjusting parameters of the model and instrument. Both Rietveld and Le Bail techniques were performed using a set of programs known as general structure analysis system (GSAS) which is written in the FORTRAN language [27]. In the GSAS, the reliability of refinement is quantified by the $R$-factors which are the weighed profile $R$-factor, $R_{\mathrm{wp}}$ and $R_{\mathrm{exp}}$, which is the expected statistical value for $R_{\mathrm{wp}}$. Another related statistical term is the agreement $\chi^{2}$ factor expressed as $\left(R_{\mathrm{wp}} / R_{\mathrm{exp}}\right)^{2}$ and the ideal value for $\chi^{2}$ is 1 . The refinement procedure for the analysis is as follows: a complex function is applied to model the peak shape known as a multi term, Simpson's rule integration of the pseudo-Voigt function, which is a combination of Gaussian and Lorentzian functions. A Chebyshev polynomial function was used to fit the background. The anomalous contributions to the X-ray, form factors of all atoms, $f^{\prime}$ and $f^{\prime \prime}$ corrections to $f$, were calculated using the program DISPANO [28] (in e per atom) for input into the GSAS as follows: zinc $f^{\prime}=-1.614$, $f^{\prime \prime}=0.677$; oxygen $f^{\prime}=-0.046, f^{\prime \prime}=0.032$ and samarium $f^{\prime}=-5.662, f^{\prime \prime}=12.303$. Profile shape coefficients in steps with intermediate refinements of zero-point correction and background function were applied together with refined lattice parameters and scale factors of the crystallographic phases. During the Rietveld analysis of $\mathrm{ZnO}$, the fractional atomic coordinates of $\mathrm{Zn}$ and $\mathrm{O}$ were also allowed to refine together with their fractional occupancies.

\subsection{FTIR, UV-visible spectroscopy and SEM}

Fourier transform infrared (FTIR) spectra of the nanoparticles were recorded on a PerkinElmer Spectrum Two FTIR spectrophotometer. The optical absorbance as a function of wavelength, in the range of $200-800 \mathrm{~nm}$, was recorded using a UV-Vis spectrophotometer. A LEO EVO $40 \mathrm{xVP}$ model scanning electron microscope (SEM) and Röntechxflash energy dispersive X-ray (EDX) detector were employed to study the morphology and elemental composition of the synthesized samples.

\section{Results}

\subsection{XRPD analysis}

XRPD data reveal that the water-based wet-chemical route results in the formation of a single-phase polycrystalline $\mathrm{ZnO}$ powder with a wurtzite hexagonal structure as reported in the literature [29]. Figure 1 shows an overplot of the collected XRPD profiles of the samples. Qualitative inspection of the Sm-doped data reveals that an impurity phase emerges with an increase in Sm content. Besides, changes in the relative peak width and intensities, and a slight shift in peak positions due to the lattice contraction, Sm-doping did not lead to a phase transition to a structure with a different crystal symmetry. For modelling the $\mathrm{ZnO}$ phase, the previously reported wurtzite structure with a hexagonal space

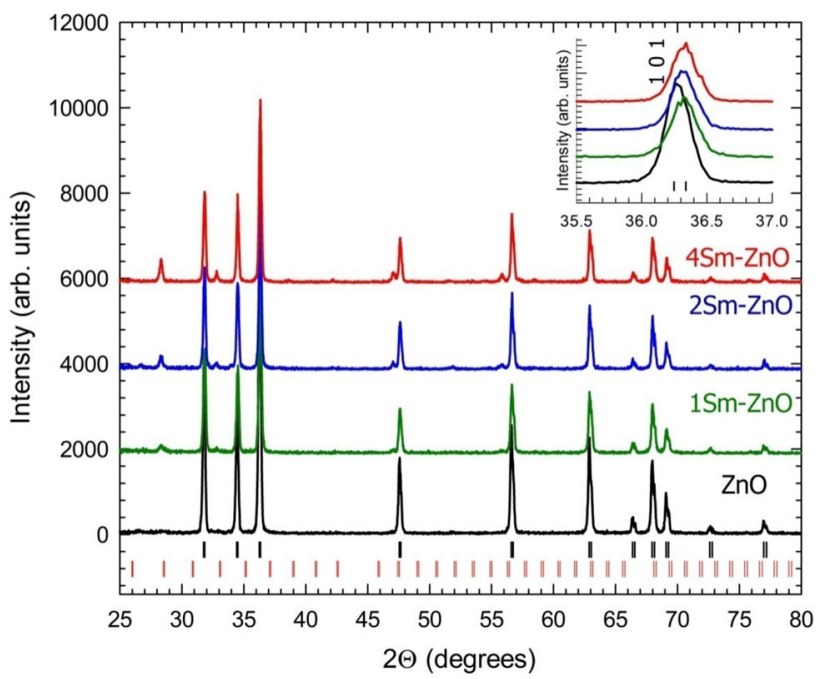

Figure 1. XRPD profiles of pristine $\mathrm{ZnO}$ and $\mathrm{Sm}$-doped $\mathrm{ZnO}$ samples collected at room temperature with $\lambda=1.5406 \AA$. Black and red ticks mark the reflection positions of co-existing hexagonal $\mathrm{ZnO}$ and cubic $\mathrm{Sm}_{2} \mathrm{O}_{3}$ structures, respectively. The inset shows an expanded view focussing on the hexagonal (101) Bragg's peak. 


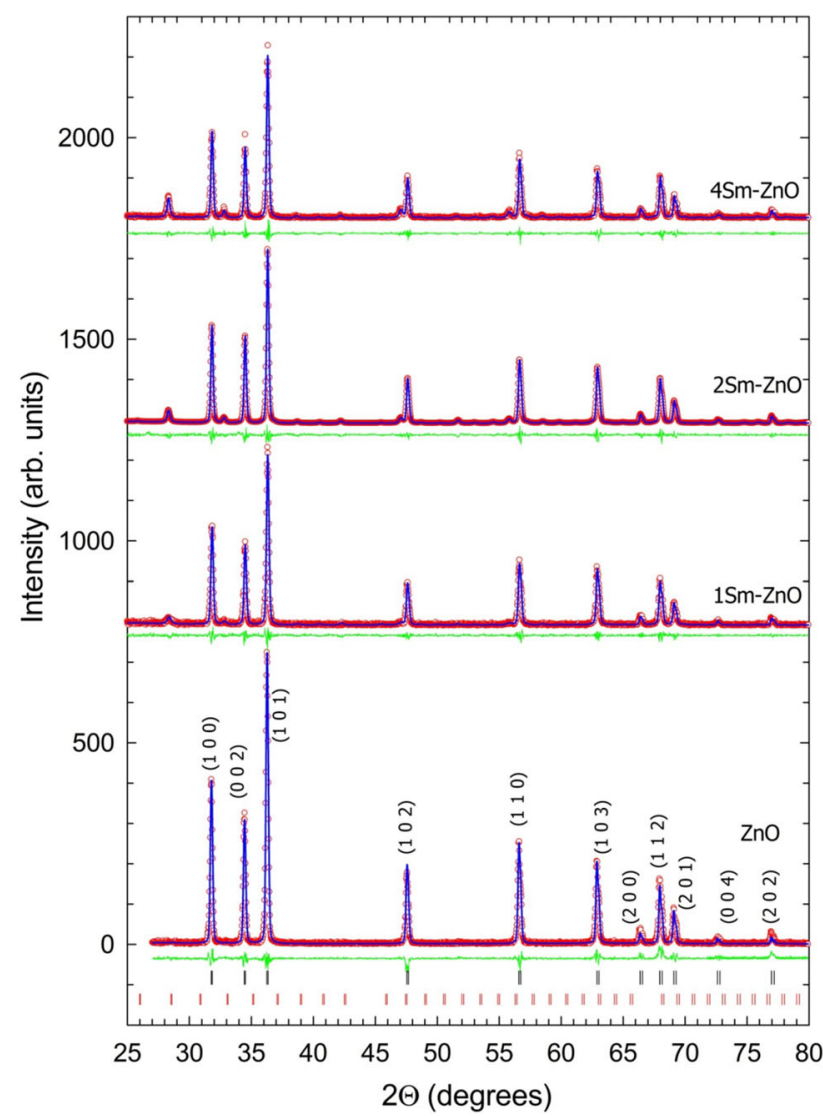

Figure 2. Rietveld fit to XRPD data collected for pristine $\mathrm{ZnO}$ (bottom) and Le Bail fits to XRPD data collected for Sm-doped ZnO compounds (tops, as labelled). Red circles, blue and green lines represent the observed, calculated and difference profiles, respectively. Black and red ticks mark the reflection positions of hexagonal $\mathrm{ZnO}$ and cubic $\mathrm{Sm}_{2} \mathrm{O}_{3}$ structures, respectively. The observed Bragg peaks are labelled by their $(h k l)$ Miller indices with the same colours as the tick marks. The weighed-profile and expected $R$ factors are $R_{\mathrm{wp}}=19.2 \%, R_{\exp }=17.6 \%(\mathrm{ZnO}), R_{\mathrm{wp}}=20.5 \%$, $R_{\exp }=18.3 \%(1 \mathrm{Sm}-\mathrm{ZnO}), R_{\mathrm{wp}}=22.8 \%, R_{\exp }=18.8 \%(3 \mathrm{Sm}-$ $\mathrm{ZnO})$ and $R_{\mathrm{wp}}=21.6 \%, R_{\exp }=19.1 \%(4 \mathrm{Sm}-\mathrm{ZnO})$.

group $P 6_{3} m c$ was employed. Refined structural parameters of hexagonal $\mathrm{ZnO}$ are as follows: the lattice constants and unit cell volume are $a=3.24927(5) \AA, c=5.2031(2) \AA$ and $V=47.574(1) \AA^{3}$, respectively, in agreement with the previously reported lattice parameters at $300 \mathrm{~K}: a=3.2489(1) \AA$ and $c=5.2053(4) \AA$ [29]. The fractional occupancies of zinc and oxygen were allowed to refine and they converged to $0.915(17)$ and $1.085(17)$, respectively, which reveal a good agreement between the refined and nominal occupancy values of 1 . Refinement of the zinc and oxygen coordinates gave a $\mathrm{Zn}-\mathrm{O}^{\mathrm{a}}$ bond length of 1.98233(5) $\AA$ and $\mathrm{Zn}-\mathrm{O}^{\prime}(\times 3)^{\mathrm{a}}=$ 1.97527(3) $\AA$, which are consistent with the reported bond lengths of 1.986(2) and 1.9745(2) $\AA$, respectively. These refined structural parameters confirm the quality of the synthesized polycrystalline $\mathrm{ZnO}$ compound.

The final Rietveld fit and Le Bail fits to the collected XRPD data of pristine $\mathrm{ZnO}$ and $\mathrm{Sm}$-doped $\mathrm{ZnO}$, respectively, and are shown in figure 2. The reason for employing the Le Bail technique rather than Rietveld for doped samples is to reliably extract the evolution of the unit cell volume with Smdoping. As seen from the figure, the observed XRPD data of $\mathrm{Sm}$-doped samples were satisfactorily modelled by including cubic samarium oxide, $\mathrm{Sm}_{2} \mathrm{O}_{3}$ (space group I2 ${ }_{1} 3$ ) [30] as a second crystallographic phase.

The fractional atomic coordinates and occupancies of $\mathrm{Sm}_{2} \mathrm{O}_{3}$ were kept as constants as per literature values, but its lattice parameters were allowed to refine. Table 1 summarizes the refined structural parameters of Sm-doped samples and co-existing phase fractions of wurtzite-structured $\mathrm{ZnO}$ and cubic $\mathrm{Sm}_{2} \mathrm{O}_{3}$. Both qualitative and quantitative investigations of the XRPD data show that with Sm-doping at a nominal level of $0.4 \mathrm{mmol}(1 \% \mathrm{Sm}): 1 \mathrm{Sm}-\mathrm{ZnO}$, a slight lattice contraction is observed in the $\mathrm{ZnO}$ hexagonal structure. One expects to observe a lattice expansion rather than a contraction due to the substitution of bigger $\mathrm{Sm}^{3+}(0.964$ $\mathrm{nm})$ for $\mathrm{Zn}^{2+}(0.74 \mathrm{~nm})$; however, this strongly depends on the presence of the lattice distortion and strain and defects induced by the slight substitution of $\mathrm{Sm}^{3+}$. For instance, while Arora et al [31] and Kumar et al [24] found a slight lattice contraction upon Sm doping. Pandiyarajan et al [26] reported a lattice expansion with Sm-doping. The observed shift in the peak positions towards higher angles, however, did not continue with an increase in the doping level of Sm, i.e., no further lattice contraction is observed within error with doping concentration of 2 and $4 \%$, which is in excellent agreement with the previously reported studies [24,31]. This trend can be tentatively attributed to a further increase in the concentration of defects and impure atoms due to the increased substitutional doping of $\mathrm{Sm}$ and size mismatch between the ions present in the structure. These reasons also led to a significant suppression of the peak intensity in the XRPD data of $1 \mathrm{Sm}-\mathrm{ZnO}$ compared to that of pure $\mathrm{ZnO}$.

Table 1. Refined structural parameters and phase fractions for pristine $\mathrm{ZnO}$ and $\mathrm{Sm}$-doped $\mathrm{ZnO}$.

\begin{tabular}{lccccc}
\hline $\begin{array}{c}\text { Nominal } \\
\text { Sm-content }\end{array}$ & $a(\AA)$ & $c(\AA)$ & $V\left(\AA^{3}\right)$ & $\begin{array}{c}\text { Hexagonal ZnO } \\
\text { phase (wt.\%) }\end{array}$ & $\begin{array}{c}\mathrm{Cubic} \mathrm{Sm}_{2} \mathrm{O}_{3} \\
\text { phase (wt.\%) }\end{array}$ \\
\hline 0 & $3.24927(5)$ & $5.2031(1)$ & $47.574(1)$ & 100 & - \\
1 & $3.24851(8)$ & $5.20183(20)$ & $47.540(2)$ & $96.80(8)$ & $3.2(2)$ \\
2 & $3.25070(7)$ & $5.20457(18)$ & $47.629(2)$ & $94.39(9)$ & $9.6(2)$ \\
4 & $3.25020(7)$ & $5.20432(18)$ & $47.612(2)$ & $90.72(7)$ & $9.3(1)$ \\
\hline
\end{tabular}


Table 2. Micro-structural parameters and optical band gap energy.

\begin{tabular}{lcccc}
\hline Parameter & Pure $\mathrm{ZnO}$ & $1 \mathrm{Sm}-\mathrm{ZnO}$ & $2 \mathrm{Sm}-\mathrm{ZnO}$ & $4 \mathrm{Sm}-\mathrm{ZnO}$ \\
\hline$X_{\mathrm{C}} \%$ & 95.3 & 93.7 & 93.6 & 94.2 \\
$D_{\mathrm{S}}(\mathrm{nm})$ & 37.15 & 38.18 & 39.07 & 41.60 \\
$D_{\mathrm{WH}}(\mathrm{nm})$ & 44.75 & 48.82 & 53.74 & 63.02 \\
Strain, $\varepsilon$ & $0.53 \times 10^{-3}$ & $1.11 \times 10^{-3}$ & $0.44 \times 10^{-3}$ & $1.37 \times 10^{-3}$ \\
Stress in the surface, $\sigma(\mathrm{MPa})$ & 55.35 & 93.77 & 44.90 & 113.96 \\
Energy density, $\left.u(\mathrm{~kJ} \mathrm{~m})^{-3}\right)$ & 16.64 & 56.58 & 10.93 & 84.17 \\
Atomic packing factor, APF\% & 75.525 & 75.476 & 75.496 & 75.504 \\
Optical band gap energy, $E_{\mathrm{g}}(\mathrm{eV})$ & 3.43 & 3.71 & 3.56 & 3.81 \\
\hline
\end{tabular}
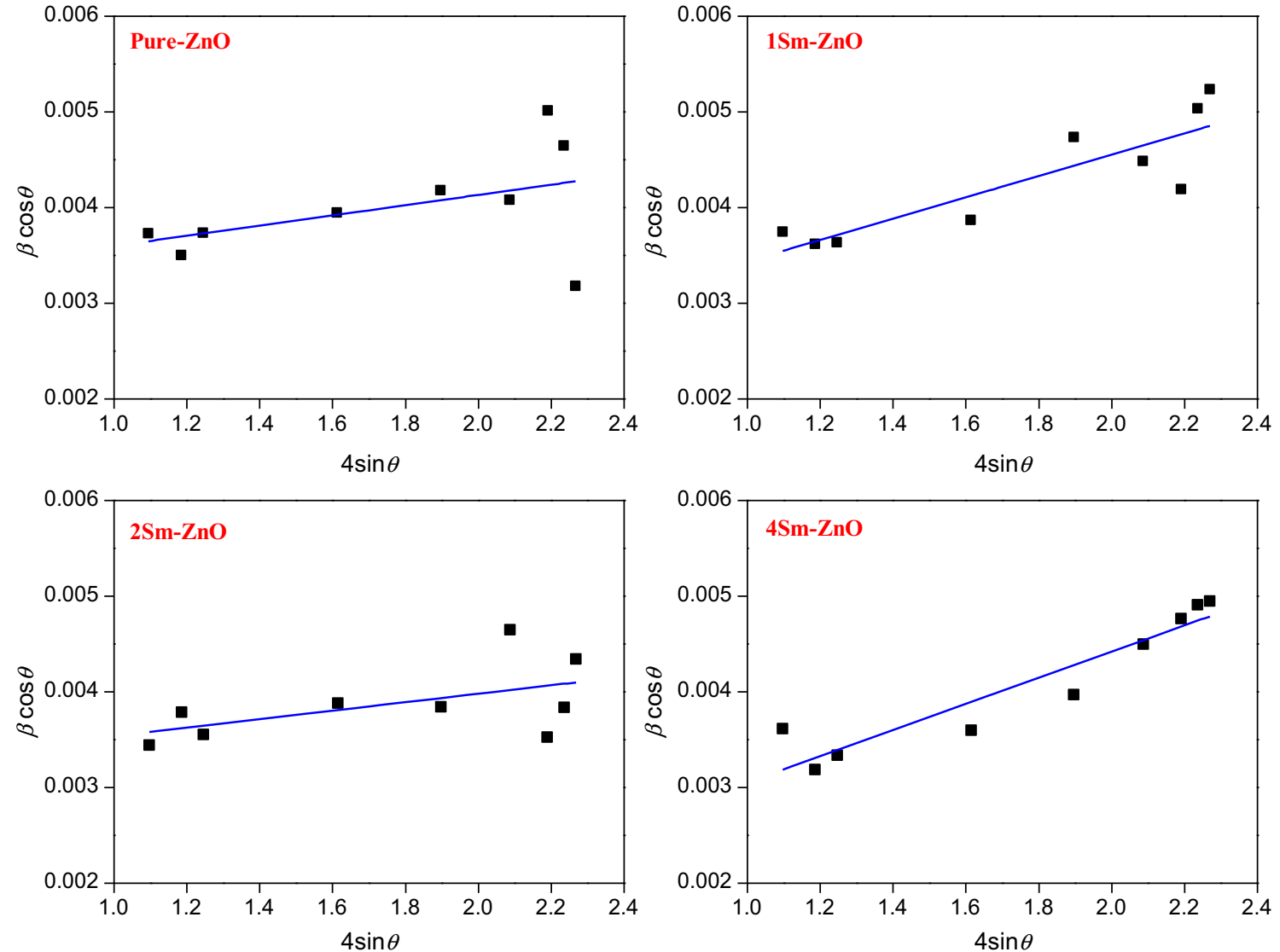

Figure 3. $\mathrm{W}-\mathrm{H}$ analysis of pure $\mathrm{ZnO}$ and $\mathrm{Sm}$-doped $\mathrm{ZnO}$ nanoparticles. Blue lines represent fit to the data, the strain is extracted from the slope and the crystalline size is extracted from the $y$-intercept of the fit.

To investigate the evolution of crystallinity percentage and crystallite size of the samples, a series of calculations were performed. The crystallinity percentage $\left(X_{\mathrm{C}} \%\right)$ was calculated using the following equation [32]:

$$
X_{\mathrm{C}} \%=\frac{\sum A_{\mathrm{C}}}{\sum A_{\mathrm{C}}+\sum A_{\mathrm{A}}} \times 100,
$$

where $\sum A_{\mathrm{C}}$ and $\sum A_{\mathrm{A}}$ are the total areas under crystalline and amorphous peaks. The calculated values of the $X_{\mathrm{C}} \%$ are shown in table 2 . The crystallinity percentage for pristine $\mathrm{ZnO}$ is calculated as $95.3 \%$, confirming high crystallinity of the material. Sm-doping does not really affect the crystallinity; a decrease of only $\sim 1.8 \%$ in $X_{\mathrm{C}} \%$ was calculated.

To evaluate the possible peak broadening with crystallite size and lattice strain induced by doping, average crystallite size $(D)$ of the samples was determined by the X-ray line broadening method using the Scherrer equation ( $D_{\mathrm{S}}$, equation (2)). In addition to that the Williamson-Hall method ( $D_{\mathrm{WH}}$, equation (3)) was applied to investigate the possible 

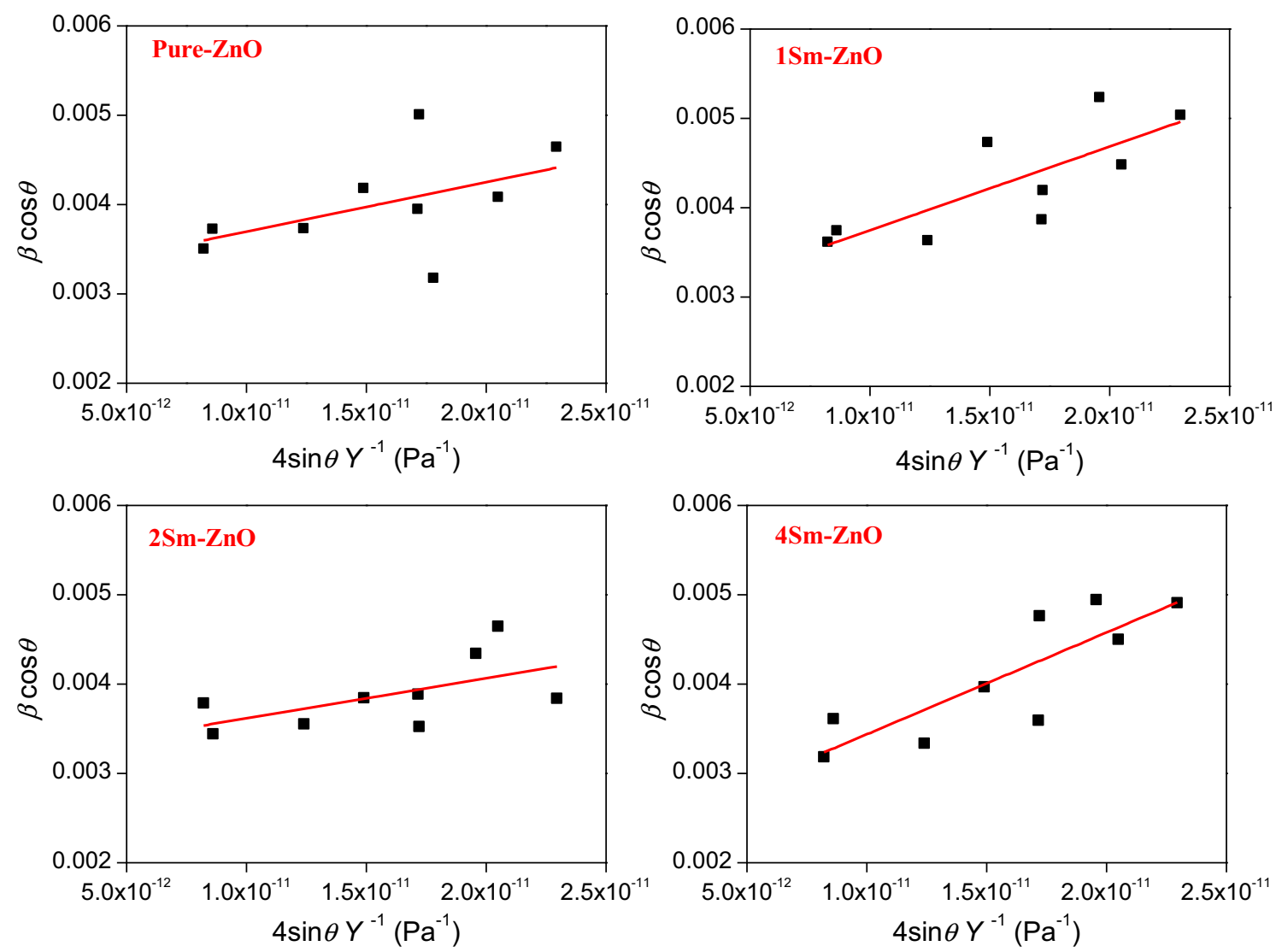

Figure 4. Modified form of W-H analysis. Red lines represent fits to the data. The stress in the surface $(\sigma)$ is extracted from the slope of the fit.

strain-induced broadening arising from crystal imperfections and distortion [33]:

$$
\begin{aligned}
D_{\mathrm{S}} & =\frac{0.9 \lambda}{\beta \cos \theta}, \\
\beta \cos \theta & =\frac{0.9 \lambda}{D_{\mathrm{WH}}}+4 \varepsilon \sin \theta,
\end{aligned}
$$

where $\beta, \theta, \lambda$ and $\varepsilon$ are the full-width at half-maximum, Bragg's angle, wavelength of the incident X-rays and lattice strain, respectively. The strain, $\varepsilon$ and particle size, $D_{\mathrm{WH}}$ are estimated by the slope and $y$-intercept of the fitted line on the $\beta \cos \theta$ vs. $4 \sin \theta$ plots (W-H plot) shown in figure 3. The $\mathrm{W}-\mathrm{H}$ plot shows that line broadening is essentially isotropic, indicating that domains are isotopically grown. The crystallite size estimated using the $\mathrm{W}-\mathrm{H}$ plot shows a similar trend to that obtained by Scherrer's equation (table 2). We found that average crystallite size, $D_{\mathrm{s}}$ increases from 37 to $42 \mathrm{~nm}$ with an increase in Sm-content up to 4\%. This implies that the calcination temperature of $900^{\circ} \mathrm{C}$ led to a significant increase in the average crystallite size with an increase in the doping level because at such high temperatures, migration of grain boundaries occurs, leading to the combination of small grains which results in the formation of large grains: this is consistent with the literature [34].

For a hexagonal crystal, the Young's modulus for each Miller indices is given by equation (4) [35], where $s_{11}$, $s_{13}, s_{33}$ and $s_{44}$ are the elastic compliances and reported to be $7.858 \times 10^{-12},-2.206 \times 10^{-12}, 6.940 \times 10^{-12}$ and $23.570 \times 10^{-12} \mathrm{~m}^{2} \mathrm{~N}^{-1}$, respectively [36].

$$
Y=\frac{\left[h^{2}+\frac{(h+2 k)^{2}}{3}+\left(\frac{a l}{c}\right)^{2}\right]^{2}}{s_{11}\left(h^{2}+\frac{(h+2 k)^{2}}{3}\right)^{2}+s_{33}\left(\frac{a l}{c}\right)^{4}+\left(2 s_{13}+s_{44}\right)\left(h^{2}+\frac{(h+2 k)^{2}}{3}\right)\left(\frac{a l}{c}\right)^{2}} .
$$



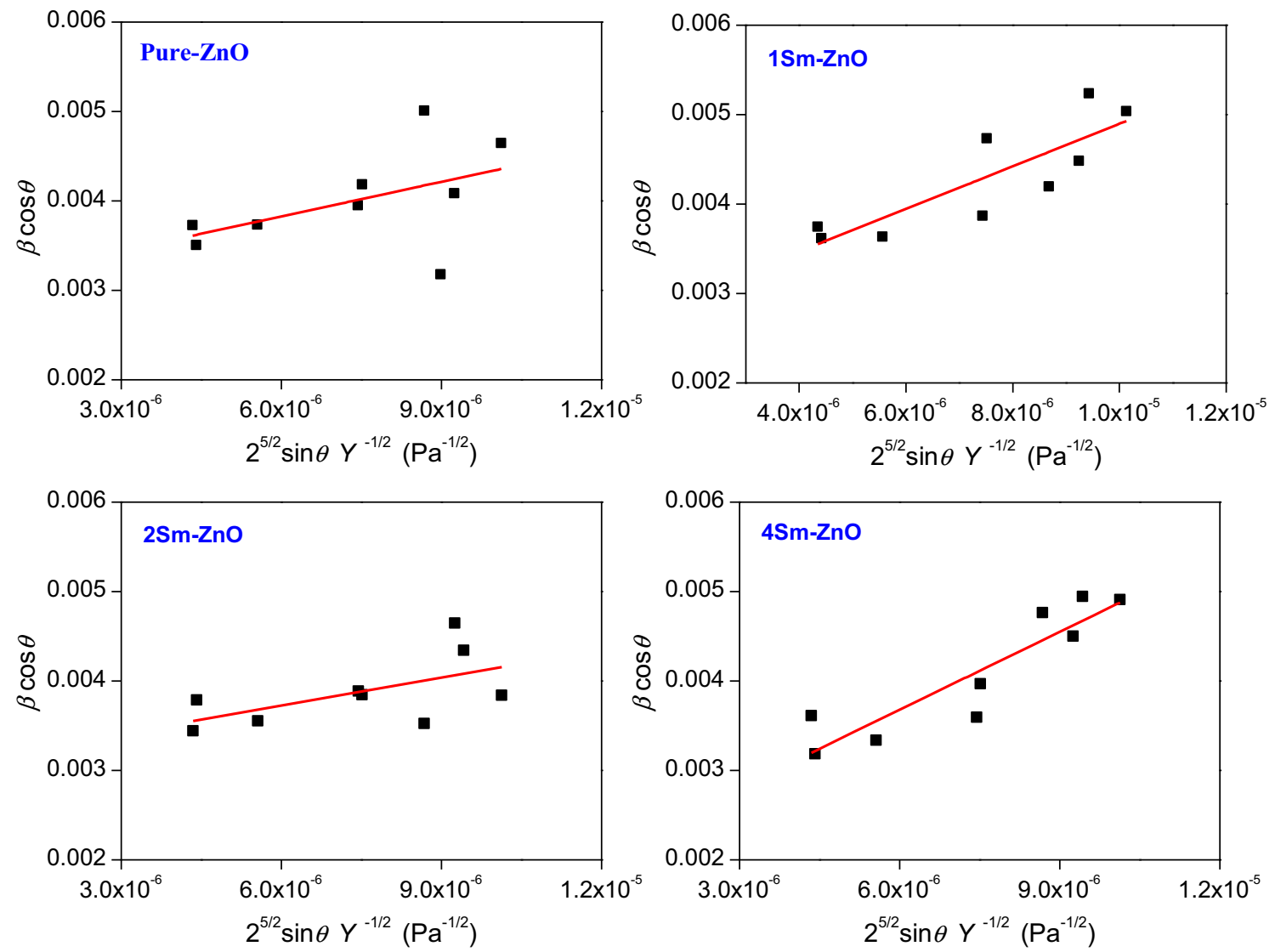

Figure 5. Modified form of $\mathrm{W}-\mathrm{H}$ analysis. Red lines represent fits to the data. The energy density $(u)$ is extracted from the square of the slope of the fit.

Using the calculated $Y$ values, the stress in the surface $(\sigma)$ and energy density ( $u$, energy per area) values for all the samples were calculated using the following equations, respectively:

$$
\begin{aligned}
& \beta \cos \theta=\frac{0.9 \lambda}{D_{\mathrm{WH}}}+\frac{4 \sigma \sin \theta}{Y}, \\
& \beta \cos \theta=\frac{0.9 \lambda}{D_{\mathrm{WH}}}+4 \sin \theta\left(\frac{2 u}{Y}\right)^{1 / 2} .
\end{aligned}
$$

The slope of the $\beta \cos \theta$ vs. $4 \sin \theta Y^{-1}$ plots shown in figure 4 gives the $\sigma$ value for each sample and the square of the slope of the $\beta \cos \theta v s .2^{5 / 2} \sin \theta Y^{-1 / 2}$ plots shown in figure 5 equals to the $u$ values. We have also calculated the atomic packing factor (APF) from the following equation [37]. The calculated APF for pristine and doped $\mathrm{ZnO}$ is $\sim 75 \%$, implying that the introduction of Sm did not lead to a significant change in packing fraction, in agreement with earlier studies $[37,38]$ :

$$
\mathrm{APF} \%=\frac{2 \pi a}{3 \sqrt{3} c} \times 100
$$

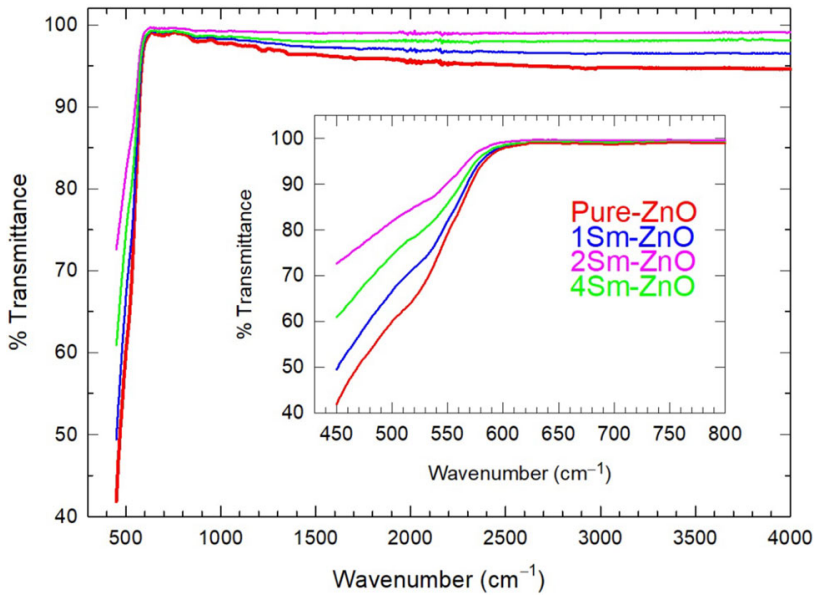

Figure 6. FTIR spectra of pristine and Sm-doped $\mathrm{ZnO}$ samples. The inset shows an expanded view focussing on the $\mathrm{Zn}-\mathrm{O}$ stretching.

\subsection{FTIR and SEM}

The FTIR spectrum (figure 6) shows the strong absorption band ranging from 450 to $550 \mathrm{~cm}^{-1}$ assigned to the $\mathrm{Zn}-\mathrm{O}$ 

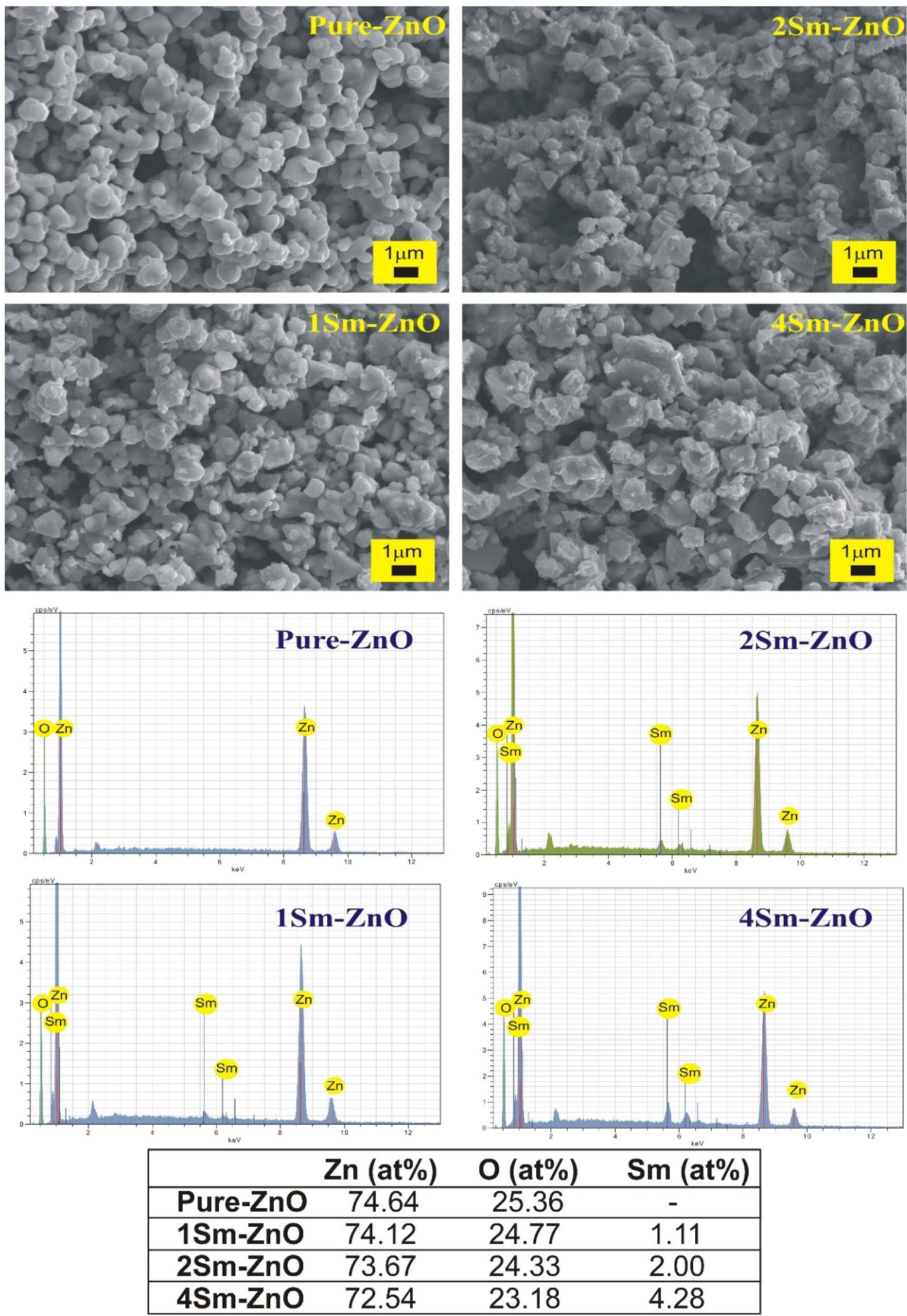

Figure 7. SEM images and EDX reports of pure and Sm-doped $\mathrm{ZnO}$ nanoparticles. 


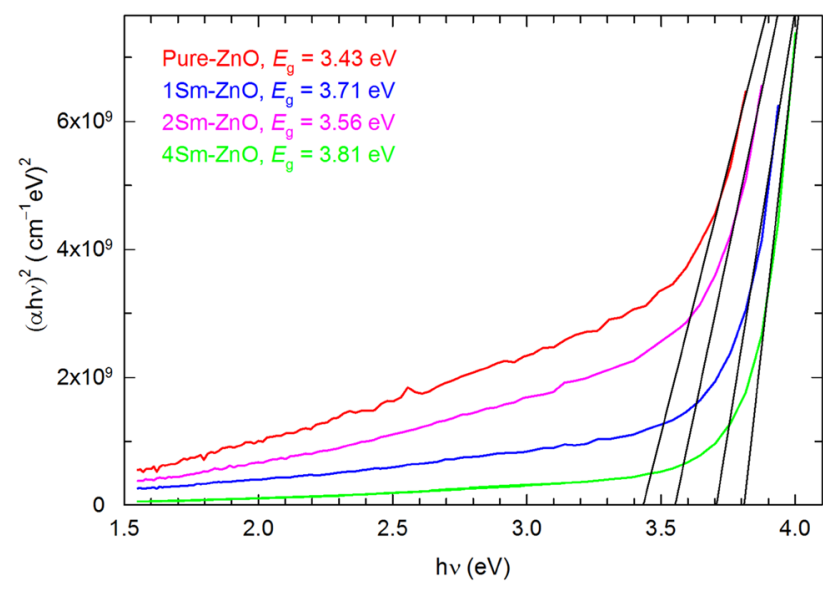

Figure 8. Energy dependence of $(\alpha h v)^{2}$ for pure and Sm-doped $\mathrm{ZnO}$ nanoparticles. The solid black lines through the data are the linear fit.

stretching vibration mode [39] for the $\mathrm{ZnO}$ and Sm-doped nanostructures. As the samples were heated up to $900^{\circ} \mathrm{C}$, no hydroxyl groups remained due to the adsorption of water. The SEM images and EDX spectrum for each sample taken at the magnification of $\times 10,000$ are shown in figure 7 . The images reveal that samples possess well defined grain boundaries and pores, and with a further increase in doping concentration, i.e., $4 \%$ in $4 \mathrm{Sm}-\mathrm{ZnO}$, the surface becomes rough and more compact, implying an enhancement in the densification of the particles. This is in good agreement with our calculated higher stress and energy density values of $4 \mathrm{Sm}-\mathrm{ZnO}$ compared with that calculated for lower Sm concentrations (table 2). The chemical compositions of the doped nanoparticles are also determined by EDX measurements, confirming virtually the same compositions with the target-doped materials.

\subsection{Determination of optical energy band gap}

As $\mathrm{ZnO}$ has a direct band gap, optical energy gap, $E_{\mathrm{g}}$ can be determined by the following Tauc's equation [40]:

$$
(\alpha h v)^{2}=C\left(h v-E_{\mathrm{g}}\right),
$$

where $\alpha$ is the absorption correction, $h v$ is the photon energy and $C$ is a constant. Figure 8 shows the relationship between $(\alpha h v)^{2}$ and the photon energy, and $E_{\mathrm{g}}$ is obtained by extrapolating the linear part of the curve in the high energy region to zero with a least squares linear fit. This gives the optical band gap of $\mathrm{ZnO}$ as $3.43 \mathrm{eV}$, which is in good agreement with $3.37 \mathrm{eV}$ reported in the literature. The estimated $E_{\mathrm{g}}$ of doped compounds are found to increase with an increase in the doping level (table 2): a maximum widening of $\sim 0.38 \mathrm{eV}$ of $E_{\mathrm{g}}$ is obtained with a maximum doping level of $4 \mathrm{Sm}-\mathrm{ZnO}$. Band gap widening with an increase in the Sm-doping level has been previously reported in $\mathrm{Sm}$-doped $\mathrm{ZnO}$ nanoparticles [41,42]. This widening obtained here is larger than the previously estimated widening values for doped $\mathrm{ZnO}$, i.e., $0.04 \mathrm{eV}$ for Al-doped (3 at.\%) and $0.19 \mathrm{eV}$ for Sm-doped $(0.75$ at.\%) $\mathrm{ZnO}$ [42]. The reason for an increase in the band gap energy was previously attributed to the quantum confinement effect [42]. Recent studies and our study confirm that the nature of the doped cations, the way that doping is carried out and the crystallite size of the doped $\mathrm{ZnO}$ nanostructures are of vital importance for determining the degree and type of band gap change [43]; therefore, subtle changes lead to conflicting reports on the behaviour of the band gap upon metal doping in $\mathrm{ZnO}$ nanostructures.

\section{Conclusion}

In conclusion, $\mathrm{Sm}$-doped $\mathrm{ZnO}$ nanoparticles were obtained using a water-based wet-chemical synthetic method. XRPD data collected on pure $\mathrm{ZnO}$ and doped samples were analysed using the Rietveld refinement and Le Bail analysis techniques, respectively. Refined lattice parameters of $\mathrm{ZnO}$ are found to be consistent with the literature values. Both qualitative and quantitative inspection of the XRPD data of $1 \mathrm{Sm}-\mathrm{ZnO}$ reveal that a slight lattice contraction with the substitution of $\mathrm{Zn}^{2+}$ in $\mathrm{ZnO}$ by the larger $\mathrm{Sm}^{3+}$ cation, i.e., decreases from 47.574 (1) to 47.540 (2) $\AA^{3}$, results in a large suppression of the peak intensity. We found no considerable difference between the crystallinity percentage of 1,2 and $4 \mathrm{Sm}-\mathrm{ZnO}$ samples. On the other hand, the average crystallite size of the samples, which are calcined at a high temperature of $900^{\circ} \mathrm{C}$, is found to increase $\sim 12 \%$ from pure $\mathrm{ZnO}$ to $4 \mathrm{Sm}-\mathrm{ZnO}$. We have also found that lattice strain and stress on the surface increase with an increase in Sm-content and the surface morphology strongly depends on the doping concentration of $\mathrm{Sm}$. The structural investigation found that doped and pure $\mathrm{ZnO}$ samples are stable up to $900^{\circ} \mathrm{C}$ at which calcination was performed. The estimated band gap energy values reveal that for doped $\mathrm{ZnO}, E_{\mathrm{g}}$ exceeds by $\sim 0.38 \mathrm{eV}$ compared with that of pure- $\mathrm{ZnO}$ and confirm the interesting phenomenon that was previously questioned: band gap narrowing and widening in doped- $\mathrm{ZnO}$ nanostructures. Therefore, this issue merits a more detailed investigation of RE-metal-doped $\mathrm{ZnO}$ materials using a well-established synthetic method with particular attention being paid to the heating treatment, which correlates well with the crystallite size and hence $E_{\mathrm{g}}$, and characterization of families of samples where the doping level systematically varied in a broad range.

\section{Acknowledgements}

We thank Y Kaya for his assistance and discussion on the determination of optical energy gaps. 


\section{References}

[1] Gleiter H 2000 Acta Mater. 481

[2] Klingshirn C 2007 ChemPhysChem 86

[3] Klingshirn C 2007 Phys. Status Solidi 2449

[4] Klingshirn C, Fallert J, Zhou H, Sartor J, Thiele C, Maier-Flaig F et al 2010 Phys. status solidi 2471424

[5] Kołodziejczak-Radzimska A and Jesionowski T 2014 Materials (Basel) 74

[6] Bagnall D M, Chen Y F, Zhu Z, Yao T, Koyama S, Shen M Y et al 1998 Appl. Phys. Lett. 702230

[7] Reynolds D C, Look D C and Jogai B 1996 Solid State Commun. 9912

[8] Wang Z L 2004 J. Phys. Condens. Matter 1625

[9] Lim J-H, Kang C-K, Kim K-K, Park I-K, Hwang D-K and Park S-J 2006 Adv. Mater. 182720

[10] Xu S and Wang Z L 2011 Nano Res. 411

[11] Shao S, Zheng K, Zidek K, Chabera P, Pullerits T and Zhang F 2013 Sol. Energy Mater. Sol. Cells 11843

[12] Ciciliati M A, Silva M F, Fernandes D M, de Melo M A C, Hechenleitner A A W and Pineda E A G 2015 Mater. Lett. 159 84

[13] Saleh R and Djaja N F 2014 Spectrochim. Acta A: Mol. Biomol. Spectrosc. 130581

[14] Fabbiyola S, Sailaja V, Kennedy L J, Bououdina M and Judith Vijaya J 2017 J. Alloys Compd. 694522

[15] Singhal S, Kaur J, Namgyal T and Sharma R 2012 Phys. B Condens. Matter $\mathbf{4 0 7} 8$

[16] Hosseini S M, Sarsari I A, Kameli P and Salamati H $2015 \mathrm{~J}$. Alloys Compd. $\mathbf{6 4 0} 408$

[17] Kundaliya D C, Ogale S B, Lofland S E, Dhar S, Metting C J, Shinde S R et al 2004 Nat. Mater. 3709

[18] Jung S W, An S-J, Yi G-C, Jung C U, Lee S-I and Cho S 2002 Appl. Phys. Lett. 804561

[19] Korake P V, Kadam A N and Garadkar K M 2014 J. Rare Earths 324

[20] Atkinson S C 2014 Crystal structures and phase transitions in the rare earth oxides, University of Salford

[21] Daksh D and Agrawal Y K 2016 Rev. Nanosci. Nanotechnol. 51

[22] Lin C C, Young S L, Kung C Y, Horng L, Chen H Z, Kao M C et al 2013 Vacuum 87178
[23] Ahmed M A, Mwankemwa B S, Carleschi E, Doyle B P, Meyer W E and Nel J M 2018 Mater. Sci. Semicond. Process. 7953

[24] Kumar D R, Ranjith K S, Nivedita L R and Kumar R T R 2017 J. Rare Earths $\mathbf{3 5} 10$

[25] Abbad M M, Takriff M S, Benamor A, Nasser M S, Mahmoudi E and Mohammad A W 2018 J. Sol-Gel Sci. Technol. 85178

[26] Pandiyarajan T, Mangalaraja R V, Karthikeyan B, Sathishkumar P, Mansilla H D, Contreras D et al 2015 Appl. Phys. A 119 487

[27] Toby B H 2001 J. Appl. Crystallogr. 342

[28] Laugier J and Bochu B 1999 LMGP-Suite of programs for the interpretation of $X$-ray experiments (ENSP/Laboratoire des Matériaux et du Génie Physique)

[29] Sawada H, Wang R and Sleight A W 1996 J. Solid State Chem. 1221

[30] Zav'yalova A A, Imamov R M, Ragimli N A and Semilatov S A 1976 Sov. Phys. Crystallogr. 21411

[31] Arora D, Asokan K, Mahajan A, Kaur H and Singh D P 2016 RSC Adv. 681

[32] Kaygili O 2014 J. Therm. Anal. Calorim. 1171

[33] Kaygili O, Ercan I, Ates T, Keser S, Orek C, Gunduz B et al 2018 Chem. Phys. 513273

[34] Kumar S S, Venkateswarlu P, Rao V R and Rao G N 2013 Int. Nano Lett. 330

[35] Zhang J-M, Zhang Y, Xu K-W and Ji V 2006 Solid State Commun. 1393

[36] Nye J F 1985 Physical properties of crystals: their representation by tensors and matrices (Oxford: Clarendon Press)

[37] Kumar P, Singh B K, Pal B N and Pandey P C 2016 Appl. Phys. A 1228

[38] Mote V D, Dargad J S and Dole B N 2013 Nanosci. Nanoeng. 12

[39] Zamiri R, Rebelo A, Zamiri G, Adnani A, Kuashal A, Belsley M S et al 2014 RSC Adv. 420902

[40] Tauc J 1966 in S Nudelman and S Mitra (eds) Optical properties and electronic structure of amorphous semiconductors (Boston: Springer US)

[41] Badreddine K, Kazah I, Rekaby M and Awad R 2018 J. Nanomater. 2018

[42] He H Y, Fei J and Lu J 2015 J. Nanostruct. Chem. 52

[43] Kamarulzaman N, Kasim M F and Rusdi R 2015 Nanoscale Res. Lett. 101 